\title{
O DIREITO BRASILEIRO E A INOVAÇÃO NA CONSOLIDAÇÃO DE UM SISTEMA DE PRECEDENTES RECURSAIS ${ }^{1}$
}

\author{
BRAZILIAN LAW AND THE NOVELTY CONSOLIDATION OF A CASE- \\ PRECEDENT APPEAL SYSTEM
}

\begin{abstract}
Albenir Itaboraí Querubini Gonçalves ${ }^{2}$
RESUMO: O presente artigo faz uma constatação e analisa o surgimento de um sistema de precedentes jurisprudenciais no sistema recursal brasileiro a partir dos diversos procedimentos processuais criados com a finalidade de solucionar demandas repetitivas através da uniformização da jurisprudência como técnica de racionalização dos julgamentos, especialmente pelos ritos dos recursos repetitivos no âmbito do Superior Tribunal de Justiça e da repercussão geral pelo Supremo Tribunal Federal.
\end{abstract}

PALAVRAS-CHAVE: precedentes jurisprudenciais, sistema recursal, uniformização da jurisprudência, recursos repetitivos.

\begin{abstract}
This article analyses the birth of a case-precedent appeal system in the Brazilian legal scenario, beginning with the many and varied case procedures adopted with the goal of solving repetitive cases through the uniformization of precedents as a rationality technique, specially through the repetitive cases procedures at the Superior Court of Justice level and the general interest criteria at the Supreme Court level.
\end{abstract}

KEY WORDS: precedents, appeal system, precedents uniformization, repetitive appeals.

\section{INTRODUÇÃO}

O Direito brasileiro está vivendo um novo e importante fenômeno, que até o momento tem passado despercebido pela maioria dos juristas e ainda é carecedor de estudos. Trata-se da adoção e consolidação de um sistema recursal de precedentes jurisprudenciais, o que é, inclusive, uma novidade no âmbito do sistema jurídico

\footnotetext{
1 O presente artigo é síntese da comunicação oral apresentada no Colóquio "Brasil Brasiliano" promovido pela Linha de Pesquisa "Inovação e Desenvolvimento Institucional brasileiro", do Grupo de Estudos e Pesquisa sobre "Inovação e Futuro", UFSM/CNPq, realizado em Santa Maria-RS, no dia 7 de maio de 2011. Registro meus agradecimentos ao pesquisador Adivo Paim Filho em nome de todos os realizadores do evento e ao meu colega e amigo Prof. Bruno Bolzon Lauda.

${ }^{2}$ Bacharel em Ciências Jurídicas e Sociais pela UFSM, Especialista e mestrando em Direito pela UFRGS. Professor de Direito Agrário, Ambiental e Contratos nos curso de pós-graduação e atualização do Instituto Universal de Marketing em Agribusiness (I-UMA) e de Direito Processual Civil - Recursos - na Prioritá Cursos, em Porto Alegre-RS. E-mail: albenir@gmail.com
} 
romano-germânico (civil law), do qual o Brasil faz parte. Sua origem decorre da experiência bem sucedida alcançada pela previsão normativa de procedimentos processuais criados para solucionar as demandas repetitivas através da uniformização jurisprudencial, como forma de racionalizar a sistemática até então adotada que permitia a sobrecarga especialmente das instâncias superiores. O presente texto, que terá uma abordagem de viés mais prático do que teórico, além de realizar a constatação de tal fenômeno, também pretende discorrer como isso se reflete na atuação do Judiciário.

\section{MULTIPLICIDADE DE RECURSOS E PLURALIDADE DE INTERPRETAÇÕES: SOBRECARGA DO JUDICIÁRIO E DIVERGÊNCIAS JURISPRUDENCIAIS NA CONTRAMÃO DA CELERIDADE E DA SEGURANÇA JURÍDICA}

No atual contexto dos regimes democráticos é indiscutível o papel do Judiciário, pois, em síntese, é a instituição estatal responsável pela resolução das controvérsias jurídicas ${ }^{3}$, através da interpretação e da aplicação das leis para a solução das demandas judiciais. A Constituição da República Federativa do Brasil promulgada em 1988 passou a garantir o amplo acesso ao Judiciário ${ }^{4}$, assim como acontece nos demais países democráticos. Por consequiência, o maior acesso ao Judiciário é uma das causas que resultaram no crescente aumento do número das demandas judiciais.

Mas para que o Judiciário consiga desempenhar com qualidade sua função institucional surge uma preocupação com o tempo de duração dos processos. Interessa à sociedade a garantia de que a prestação jurisdicional ocorra de forma célere,

\footnotetext{
${ }^{3}$ Conforme o autor italiano Carlo Guarnieri, é característica do procedimento judicial o fato de, uma vez provocado pelas partes, suas demandas são julgadas por juízes que não podem ser previamente escolhido por elas (terceiro imparcial), ao contrário de outros procedimentos (mediação e arbitragem), e de ficarem obrigadas a respeitar tais decisões. Carlo GUARNIERI. Magistratura e Politica in Italia: pesi senza contrappesi. Bolonha: Il Mulino, 1992.

${ }^{4}$ É o que prevê o artigo $5^{\circ}$, inciso XXV, da Constituição da República de 1988: "a lei não excluirá da apreciação do Poder Judiciário lesão ou ameaça a direito".
} 
assegurando a razoável duração dos $\operatorname{processos}^{5}$ e evitando a chamada "morosidade judicial”, que sempre é alvo de críticas da sociedade em relação ao Judiciário.

Entre principais causas da morosidade judiciária está a possibilidade da interposição de inúmeros recursos contra as decisões proferidas pelas diversas instâncias jurisdicionais. Deve ficar claro que o simples fato de existir a previsão de recursos e a sua utilização pelas partes demandantes não é propriamente uma das causas da morosidade do Judiciário, já que a possibilidade de recorrer das decisões é uma garantia processual que deve ser assegurada as partes. O problema surge quando o sistema processual possibilita a interposição de inúmeros recursos sobre as mesmas questões de direito diversas vezes em processos diferentes, permitindo inclusive a interposição de novos recursos sobre matérias já julgadas. Não se pode deixar de registrar uma grande parcela de culpa do Poder Público, que é o responsável pela maioria da demanda judicial e dos recursos que chegam ao Judiciário. Isso porque o Poder Público possui como regra geral a adoção da prática processual da utilização de inúmeros recursos, visando ao esgotamento das instâncias. A consequiência disso é a sobrecarga da máquina do Judiciário, especialmente nas instâncias superiores, que acabam julgando várias vezes recursos de idêntico objeto.

Tal situação é agravada ainda mais quando ocorrem divergências de entendimentos. Pois, como explicar aos demandantes que num mesmo caso uma das partes consegue obter êxito enquanto que a outra acaba sucumbindo? A consequiência direita é a insegurança jurídica e o descrédito com relação ao Judiciário, que acaba afetando a sociedade como um todo, especialmente no campo econômico-empresarial em que o grau de investimentos está diretamente associado à segurança das relações jurídicas. Além disso, tal sistemática acaba criando um ciclo vicioso, pois as divergências de entendimentos entre os magistrados e os Tribunais na interpretação do direito acabam se tornando fontes de novas demandas judiciais e da interposição de novos recursos, andando na contramão da celeridade e da segurança jurídica na prestação jurisprudencial.

5 Registra-se que Emenda Constitucional $n^{\circ} 45$ acrescentou o inciso LXXVIII ao artigo $5^{\circ}$ da Constituição da República de 1988, constitucionalizando a previsão da razoável tramitação dos processos, ao prever que "a todos, no âmbito judicial e administrativo, são assegurados a razoável duração do processo e os meios que garantam a celeridade de sua tramitação". 


\section{A RACIONALIZAÇÃo DO SISTEMA PELO SURGIMENTO DE PROCEDIMENTOS PROCESSUAIS ESPECÍFICOS PARA OS CASOS DE RECURSOS REPETITIVOS E O NASCIMENTO DE UM SISTEMA DE SISTEMA DE PRECEDENTES JURISPRUDENCIAIS}

A inovação no tratamento de demandas repetitivas teve seu nascimento a partir dos procedimentos introduzidos a partir da Lei dos Juizados Especiais Federais, Lei $\mathbf{n}^{\mathbf{o}}$ 10.259, de 12 de julho de 2001, ao prever que recursos de pedido de uniformização e recursos extraordinários idênticos interpostos contra as decisões proferidas pelas Turmas Recursais ficarão retidos aguardando o pronunciamento das instâncias superiores nos processos representativos das controvérsias previamente remetidos ${ }^{6}$. A referida medida, embora simples, representou uma grande novidade no sentido de uma racionalização no tratamento dos recursos repetitivos.

Na prática, ao verificar a existência de recursos idênticos sobre a mesma questão de direito, ocorre a remessa de apenas alguns processos representativos da controvérsia à instância superior para apreciação da questão, sendo que os demais processos idênticos ficam sobrestados aguardando o julgamento daqueles processos. A decisão proferida pela instância superior nos processos representativos passa a vincular os demais processos que ficaram aguardando. Assim, há a racionalização dos procedimentos, pois a não há lógica para a instância superior julgar várias vezes inúmeros recursos idênticos, quando é possível julgar apenas uma vez a questão controvertida solucionando vários processos ao mesmo tempo.

Posteriormente à sistemática introduzida no modelo recursal dos Juizados Especiais Federais, outras inovações processuais foram introduzidas também no rito comum. É o caso que se observa com a sistemática da Repercussão Geral pelo Supremo Tribunal Federal e do Rito dos Recursos Repetitivos pelo Superior Tribunal de Justiça.

\footnotetext{
${ }^{6}$ De acordo com os artigos 14, §§ 6 , e 15 da Lei $n^{\circ} 10.259 / 2001$. Outras disposições específicas à tramitação dos recursos cabíveis contra as decisões das Turmas Recursais dos Juizados Especiais Federais estão previstas no Regimento Interno da Turma Nacional de Uniformização. Registra-se que a redação da Lei $n^{\circ} 10.259 / 2001$ é, por vezes, confusa e muito genérica. Por tal razão, a maior parte das rotinas relativas ao sistema recursal dos juizados foram regulamentadas por meio de resoluções, como é o caso do atual Regimento Interno da Turma Nacional de Uniformização, que foi aprovado pela Resolução $\mathrm{n}^{\circ}$ 22, de 04 de setembro de 2008, e da Resolução nº 061, de 25 de junho de 2009, ambas do Conselho da Justiça Federal.
} 
Registra-se também a previsão da edição de Súmulas Vinculantes pelo Supremo Tribunal Federal.

O procedimento da repercussão geral foi introduzido pela Emenda Constitucional $n^{\circ}$ 45/2004 e regulamentada pela Lei $n^{\circ} 11.418 / 2006$, que acrescentou os artigos 543-A e 543-B ao Código de Processo Civil. Além de permitir a racionalização dos julgados, a sistemática da repercussão geral também serve de filtro aos recursos, pois, a partir dessa nova sistemática, o Supremo Tribunal Federal passa a julgar apenas as controvérsias baseadas em questões constitucionais que apresentam relevância do ponto de vista econômico, político, social ou jurídico, que ultrapassam os limites subjetivos da causa ${ }^{7}$. Com isso, o Supremo Tribunal Federal reforça sua função de Corte Constitucional evitando que tenha de se manifestar sobre questões sem relevância constitucional para a sociedade ${ }^{8}$.

A sistemática da repercussão geral, embora similar àquela que surgiu no âmbito recursal dos Juizados Especiais Federais no que se refere às demandas repetitivas, introduziu novos procedimentos e criou novas ferramentas de controle da jurisprudência. Quando o recurso chega ao Supremo Tribunal Federal é apreciado objeto da demanda e os ministros decidem se a matéria possui ou não repercussão geral. Decidindo pela inexistência da repercussão geral, restaram automaticamente prejudicados todos os recursos idênticos. No entanto, decidindo pela existência da repercussão geral, posteriormente há o julgamento do mérito da questão. Nesse caso, todos os demais recursos idênticos a essa matéria ficam sobrestados no Tribunal ou Turma Recursal de origem aguardando o pronunciamento do Supremo Tribunal Federal, inclusive podendo proceder à devolução à origem dos processos idênticos que foram remetidos ao Supremo Tribunal Federal. O julgamento do mérito da questão passa a vincular todos os demais processos em que foram interpostos recursos que versam sobre o mesmo objeto da controvérsia, inclusive aplicando-se aos novos recursos interpostos posteriormente ao julgamento do Supremo Tribunal Federal. Nesse caso, se as decisões

\footnotetext{
${ }^{7}$ Conforme questão de ordem definida na oportunidade do julgamento do Agravo de Instrumento $\mathrm{n}^{\circ}$ 664.567/RS, o Supremo Tribunal Federal definiu que a obrigatoriedade da demonstração formal e fundamentada da repercussão geral das questões constitucionais pelos recorrentes, como condição de admissibilidade recursal, a partir 03 de maio de 2007, data da publicação da Emenda Regimental 21/2007, do Regimento Interno do Supremo Tribunal Federal.

8 Por exemplo, não é lógico, diante da importância de sua função, que o Supremo Tribunal Federal tenha que apreciar recursos que versam sobre brigas entre condôminos ou sobre a guarda de animais domésticos entre casais divorciados, como já ocorreu no passado.
} 
recorridas estão em conformidade com a decisão do Supremo Tribunal Federal considerar-se-ão prejudicados os recursos interpostos. Por outro lado, caso estejam em desconformidade com o decidido, os processos serão encaminhados para retratação pelo Tribunal ou Turma Recursal, ou seja, para adequar as decisões das instâncias inferiores à orientação uniformizada 9 .

A importância do procedimento da repercussão geral está no fato de que o Supremo Tribunal Federal passa a uniformizar a interpretação constitucional apenas uma vez, sem a necessidade de julgar vários recursos idênticos sobre a mesma questão constitucional. Com isso, há a racionalização do trabalho e o desafogamento do Supremo Tribunal Federal.

Posteriormente, surgiu o procedimento para o julgamento de recursos repetitivos no âmbito do Superior Tribunal de Justiça com a edição da Lei ${ }^{\circ} 11.672$, de 8 de maio de 2008, que acrescentou o art. 543-C ao Código de Processo Civil ${ }^{10}$. A sistemática é idêntica à sistemática da repercussão geral, diferindo apenas quanto à matéria, que no caso do rito dos recursos repetitivos tem por finalidade uniformizar a interpretação das normas infraconstitucionais. De acordo com a Constituição da República de 1988, compete ao Superior Tribunal de Justiça julgar em última instância as questões de matéria infraconstitucional. Em outras palavras, é o Superior Tribunal de Justiça quem detém a autoridade de uniformizar a interpretação das questões infraconstitucionais. Por conseqüência, as decisões proferidas pelo Superior Tribunal de Justiça em sede do rito dos recursos repetitivos passam a vincular todas as demais instâncias do Judiciário, causando a imediata superação dos entendimentos divergentes anteriormente adotados pelos Tribunais e Turmas Recursais dos Juizados Especiais Estaduais e Federais ${ }^{11}$.

\footnotetext{
${ }^{9}$ Todas as informações sobre o procedimento e as matérias submetidas ao procedimento da repercussão geral estão disponíveis no portal eletrônico do Supremo Tribunal Federal, no seguinte endereço: $<w w w . s t f . j u s . b r\rangle$. Sobre o assunto, também se indica a leitura do relatório da repercussão geral também divulgado no portal do Supremo Tribunal Federal, disponível no seguinte endereço: <http://www.stf.jus.br/portal/cms/verTexto.asp?servico=jurisprudenciaRepercussaoGeralRelatorio〉. Acesso em 17 mai. 2011.

${ }^{10}$ Os procedimentos relativos ao processamento e julgamento dos recursos especiais repetitivos previstos pela Lei $n^{\circ} 11.672 / 2008$ foram regulamentados pela Resolução n ${ }^{\circ} 8$, de 7 de agosto de 2008, do Superior Tribunal de Justiça.

${ }^{11}$ As informações sobre as matérias submetidas ao procedimento do rito dos recursos repetitivos estão disponíveis no portal eletrônico do Superior Tribunal de Justiça, no seguinte endereço: www.stj.jus.br.
} 
Outro instrumento processual inovador é a súmula vinculante ${ }^{12}$, que surgiu com a Emenda Constitucional no 45, de 30 de dezembro de 2004, que acrescentou o artigo 103-A a Constituição da República de 1988. Segundo as disposições normativas, o Supremo Tribunal Federal pode "de ofício ou por provocação, mediante decisão de dois terços dos seus membros, após reiteradas decisões sobre matéria constitucional, aprovar súmula que, a partir de sua publicação na imprensa oficial, terá efeito vinculante em relação aos demais órgãos do Poder Judiciário e à administração pública direta e indireta, nas esferas federal, estadual e municipal" ${ }^{, 13}$. É justamente no caráter vinculante que reside o principal diferencial da súmula vinculante em relação aos ritos da repercussão geral e dos recursos repetitivos, já que esses últimos, em tese, não obrigam os demais órgãos da Administração Pública a seguirem os entendimentos uniformizados. Além disso, o enunciado das súmulas vinculantes aplica-se de imediato a todos os processos em tramitação, sendo irrelevante o fato de existir ou não recursos interposição previamente ao pronunciamento do Supremo Tribunal Federal, tornando sem efeito quaisquer decisões ou entendimentos em sentido contrário ou divergente.

\section{REFLEXOS DA ADOÇÃO DO SISTEMA DE PRECEDENTES JURISPRUDENCIAIS NA ATUAÇÃO INSTITUCIONAL DO JUDICIÁRIO E A NECESSIDADE DA CONSOLIDAÇÃO DE UMA NOVA CULTURA JURÍDICA ADAPTADA ÀS MUDANÇAS}

Os procedimentos analisados até aqui permitem concluir que a adoção do sistema de precedentes jurisprudenciais já é uma realidade que se consolida no ordenamento brasileiro e marca uma nova fase do Direito brasileiro. É uma experiência promissora, que certamente irá influenciar o ordenamento jurídico de outros países, e, em perspectiva de futuro, tende a ser ampliada e aprimorada.

\footnotetext{
${ }^{12}$ Para um estudo aprofundado sobre a súmula vinculante, remetemos à seguinte obra: COSTA, Sílvio Nazareno. Súmula vinculante e reforma do Judiciário. Rio de Janeiro: Forense, 2002.

${ }^{13}$ A Lei $n^{\circ} 11.417$, de 19 de dezembro de 2006, e o Regimento Interno do Supremo Tribunal Federal regulamentam o artigo 103-A da Constituição e as demais disposições referentes ao procedimento de edição, revisão ou cancelamento de enunciado da súmula vinculante.
} 
No entanto, agora, necessita-se aprender a lidar com essa nova sistemática, que demandará o surgimento de uma cultura jurídica adaptada a essa nova realidade. Isso porque a adoção dessa nova sistemática de precedentes jurisprudenciais exige uma nova forma de raciocinar os processos, requerendo adaptações, mudanças de procedimentos e, inclusive, reflexões sobre a prática jurídica no sentido de viabilizar superar das resistências a tais mudanças.

Sem dúvidas, essa nova experiência jurídica do Direito Brasileiro já colhe frutos positivos no sentido da melhoria da atuação institucional do Judiciário, ao permitir uma racionalização do sistema, além de se apresentar como uma solução para a problemática da chamada morosidade da máquina judiciária e viabilizar uma maior segurança jurídica ao eliminar os principais pontos de divergências interpretativas. Por decorrência lógica, essa nova experiência jurídica reflete diretamente numa economia processual em sentido amplo, pois viabiliza maior celeridade processual e redução de custos, melhorando a eficiência do Judiciário na resolução das controvérsias.

Vivenciamos, assim, o nascimento de uma nova fase do Direito brasileiro.

\section{REFERÊNCIAS}

Carlo GUARnIERI. Magistratura e Politica in Italia: pesi senza contrappesi. Bolonha: Il Mulino, 1992.

BRASIL. Constituição Federal de 1988.

BRASIL. Supremo Tribunal Federal. Relatório da repercussão geral. Disponível em: <http://www.stf.jus.br/portal/cms/verTexto.asp? servico=jurisprudenciaRepercussaoGeralRelatorio〉. Acesso em 17 mai. 2011.

COSTA, Sílvio Nazareno. Súmula vinculante e reforma do Judiciário. Rio de Janeiro: Forense, 2002. 